\title{
Study of pH System in Common Effluent Treatment Plant
}

\author{
B. Meenakshipriya (Corresponding author) \\ Department of Mechatronics Engineering, Kongu Engineering College \\ Perundurai, Erode - 638052, Tamilnadu, India
}

Tel: 91-098-4279-9990Ｅ-mail: devameena@rediffmail.com

Dr.K.Saravanan

Department of Chemical Engineering, Kongu Engineering College

Perundurai, Erode - 638052, Tamilnadu, India

Tel: 91-098-4270-5656 E-mail: rumisivaesh@yahoo.com

R.Shanmugam

Perundurai Common Effluent Treatment Plant

Perundurai, Erode - 638052, Tamilnadu, India

Tel: 91-098-4324-1123

S.Sathiyavathi

P.G Scholar, Department of Mechatronics Engineering, Kongu Engineering College

Perundurai, Erode - 638052, Tamilnadu, India

Tel: 91-098-4339-9667Ｅ-mail: sathiyavathisasikumar@yahoo.co.in

\begin{abstract}
This investigation considers the study of $\mathrm{pH}$ system in Common effluent treatment plant (CETP). For this purpose, Perundurai Common Effluent Treatment (PCETP) is taken for study. Waste from textile industries is rarely neutral. Certain processes such as reactive dyeing require large quantities of alkali but pre-treatments and some washes can be acidic. It is therefore necessary to adjust the $\mathrm{pH}$ in the treatment process to make the wastewater neutral. This is particularly important if biological treatment is being used, as the microbes used in biological treatment require a $\mathrm{pH}$ in the range of 6-8 and will be killed by highly acidic or alkali wastewater. In PCETP, the wastewater is mostly alkali wastes (high $\mathrm{pH})$. For this purpose, hydrochloric acid $(\mathrm{HCl})$ is added to maintain the $\mathrm{pH}$ value from 7.5 to 7.8 to save the microbes used in biological treatment as well as to reduce the wastage of chemicals.
\end{abstract}

Keywords: pH system, CETP, PCETP, Alkali wastes, $\mathrm{HCl}$

\section{Introduction}

The textile industry occupies an important place in the economy of India and other developing countries. Textile processing consumes enormous quantity of water and chemicals for various operations like washing, dyeing, etc. The low efficiency of chemical operations and spillage of chemical cause, a significant pollution hazard and make the treatment of discharged wastewater a complex problem. Most of the wastewater treatment plants recently adopt methods of chemical precipitation and subsequent clarification. Group of textile industries are joined together to form common effluent treatment plant to economize the process.

In CETPs, raw wash effluents from various textile units are collected homogenized and then pumped to flash mixer where flocculants and lime solution are added. The flocculants addition leads to particles destabilization and it very effective in removing the dyes. Since the addition of flocculants decrease alkalinity, lime is dosed to prevent abnormal decrease in $\mathrm{pH}$ value, which may affect the flocculation. The effluent from the flash mixer flows to the clariflocculator 
where the polyelectrolytes is dosed which assist in particle bridging and compaction of the sludge. The overflow from the clarilflocculator is transferred to the sand filter to a static mixer where sodium hypochlorite is added to remove any remaining organic and residual color. The sludge thus formed is transferred to the thickener for concentration of solids and dewatered in a centrifuge. The dewatered sludge from the centrifuge is allowed to stabilize and allowed to dry in sludge drying beds (Baskar, R., 2006).

The industrial pollution control regime in India is based on the standards and regulation approach. Source specific concentration based standard have been laid down for polluting units and penalties for non compliance, disconnection of electricity/water supply and closure of the units. The standards are same for large and medium units as well as for small units. While most of the large and medium polluting units have been able to erect and operate effluent treatment plants, this option does not appear to be viable for many small units because of their small size, and technical, financial and managerial constraints. Common effluent treatment plants are being suggested as a cost-effective option for compliance with the standards for small polluting units in industrial clusters (Shankar, U., 2003).

Most process plants generate a wastewater effluent that must be neutralized prior to discharge or reuse. Consequently, $\mathrm{pH}$ control is needed in just about every process plant, and yet a large percentage of $\mathrm{pH}$ loops perform poorly. Results are inferior product quality, environmental pollution, and material waste. With ever increasing pressure to improve plant efficiency and tighter regulations in environmental protection, effective and continuous $\mathrm{pH}$ control is highly desirable. However, implementing a $\mathrm{pH}$ system is like putting a puzzle together. It will only work when all the components are in place. The $\mathrm{pH}$ puzzle includes effective $\mathrm{pH}$ probes, actuators, and controllers. The challenge is to provide a controller that is able to deal with large nonlinear gain changes in the $\mathrm{pH}$ loop. It will be useful for not only wastewater neutralization, but also chemical concentration control, since concentration is a key quality variable. Various chemicals are used for $\mathrm{pH}$ control. For acidic wastes (low $\mathrm{pH}$ ) sodium hydroxide, sodium carbonate, calcium carbonate or calcium hydroxide, may be added among other things. For alkali wastes (high $\mathrm{pH}$ ), sulphuric acid or hydrochloric acid may be added. Acids can cause corrosion of equipment and care must be taken in choosing which acid to use. Hydrochloric acid is probably better from an environmental view point but can corrode stainless steel therefore plastic or appropriately coated pumps and pipes must be used (OMEGA Engineering, 2006).

A rough indication of $\mathrm{pH}$ can be obtained using $\mathrm{pH}$ papers or indicators, which change color as the $\mathrm{pH}$ level raises. These indicators have limitations on their accuracy. Most accurate $\mathrm{pH}$ measurements are obtained with a $\mathrm{pH}$ meter. A $\mathrm{pH}$ measurement system consists of three parts: a $\mathrm{pH}$ measuring electrode, a reference electrode and a high input impedance meter. Temperature compensation is contained within the instrument, because $\mathrm{pH}$ electrodes and measurement are temperature sensitive (Samiya Ahmed, 2006). Titration is the popular method for determining total acidity on basicity of a solution. An acid/base titration curve is a plot of $\mathrm{pH} \mathrm{Vs}$ reagent addition and graphically shows how $\mathrm{pH}$ changes per unit addition of reagent. Basically, a $\mathrm{pH}$ control system measures the $\mathrm{pH}$ of the solution and controls the addition of a neutralizing agent to maintain the solution at the $\mathrm{pH}$ of neutrality or within certain acceptable limits. It is, in effect, a continuous titration. These $\mathrm{pH}$ control systems are highly varied and design depends on such factors as flow, acid or base strength or variability of strength, method of adding neutralizing agent, accuracy of control (Emerson Process Management, 2004).

\section{Overview of Common Effluent Treatment Plant (CETP, SIPCOT - Perundurai)}

Textile is a major source of income and of great importance for India's economy. At the same time textile processing has major environmental impact. A large proportion of the environmental issues are related to the use and discharge of water. Textile manufacturing is among the major industrial water users. To produce one $\mathrm{kg}$ of textile fabrication about 200 liters of water is used.

A lot of chemicals are added to the process for cleaning and dyeing purposes. Obviously the wastewater effluent from this unit contains considerable amounts of hazardous pollutants, and where heavy metals are very common. In India most of the effluent from the textile industry is discharged untreated into rivers. Today $70 \%$ of available water in India is polluted and two thirds of illness in India is related to water-borne diseases.

Water treatment is a very important step to change these conditions and to achieve a sustainable situation. India's government has an awareness of this and limits for water effluent quality exist. Unfortunately, this regulation is not closely supervised and a lot of places do not follow the regulation. In newly developed industrial areas advanced wastewater treatment is used for textile effluent, as the one in this study area SIPCOT in Perundurai.

\subsection{SIPCOT}

The government is promoting industrial growth in backward and hitherto underdeveloped areas that have potential to grow. SIPCOT is an organization arranging this in the state of Tamil Nadu. Companies, willing to start up industries in that area, lease the land for 99 years and are guaranteed good infrastructure, electricity, sewage and water supply 24 hours a day. 


\subsubsection{SIPCOT Perundurai}

SIPCOT Perundurai was started in the year 2000 and it is divided into two parts, the east and the west part, totally 1240 ha. SIPCOT only leases 732 ha of the total area and today 288 ha of the area is licensed. Currently 210 industries are located in the area within the fields of chemicals, textiles industries, food manufacturing, tanning and engineering products. SIPCOT has a common sewage plant, where black water from all industries is treated. The water comes by gravity in stone-laid drainage pipes and is then taken care of by oxidization ponds.

SIPCOT Perundurai industrial plan is an area designed for 54 different units within textile processing. The processes run at the textile industries are dyeing, bleaching and yarning. The industries in SIPCOT are mainly working with cotton. The cotton contributes with much organic matter in the water effluent. Each of the industries has two different pipe systems for wastewater. One system is taking care of the water from the first washing after dying, called the dye bath effluent. This water has always very high TDS, over $2100 \mathrm{mg} / \mathrm{l}$ and is therefore not measured. The other system is for the remaining effluents from acid wash, water washing, soap washing and softening water. All this is called wash water. The industries have a sensor that measures the TDS value from the wash water, ensuring that it does not exceed $2100 \mathrm{mg} / \mathrm{l}$. If the value is higher a valve will close and direct the water back to the receiving tank to dilute with the other wash water. The textile has two different effluent wastewater streams. The dye bath has a high TDS, above $2100 \mathrm{mg} / \mathrm{l}$, and the wash water has a lower TDS, below $2100 \mathrm{mg} / \mathrm{l}$. Each industry will also measure the flow in both effluent pipes. All effluent from the industries is sent to Perundurai Common Effluent Treatment Plant, PCETP.

\subsubsection{Perundurai Common Effluent Treatment Plant}

Each industry bears the responsibility for dealing with the effluent water from their processing. Therefore the 14 textile units together formed PCETP. Each of the units has different shares in the treatment plant and consequently they are allowed different maximum flows that they can discharge to the treatment plant. The treatment plant only handles industrial effluent from those 14 textile industries. PCETP can operate $3600 \mathrm{~m} 3 / \mathrm{d}$ wash water and $450 \mathrm{~m} 3 / \mathrm{d}$ dye bath.

\subsubsection{Dye bath treatment plant}

The dye bath treatment uses an evaporator for cleaning the water. Before the evaporator the water is pre-treated in the form of sedimentation and fine screening. The evaporation unit is a high technology system that vaporizes the water in five different evaporation tanks, three falling and two forced circulation (vacuum) tanks. They reduce the power input by using two heat exchangers and by doing so recover heat from the outgoing water to the incoming water. The outcomes from the evaporation tanks are two different waters, distilled water that goes back to the industries and the second water that goes to solar dryer ponds. The water in the solar dryer ponds evaporates to the atmosphere in 10 days. The rest consists to $95 \%$ of sodium chloride, $\mathrm{NaCl}$. The salt is collected from the bottom of the ponds and stored in sacks under roof. They produce 3.6 tons of salt each day and the space for storage is limited so this soon becomes a big and critical issue. At the time of writing an investigation is being made about purifying the salt so it can be reused in the textile industries.

\subsubsection{Wash water treatment plant}

The wash water treatment plant was opened in July 2002 and reduces COD and BOD by $40-60 \%$. They regularly measure $\mathrm{pH}, \mathrm{TSS}, \mathrm{BOD}, \mathrm{COD}$ and TDS. The plant has no seasonal variation as the textile industry produces the same quantity the throughout the year. However, the hourly inflow varies widely in both quality and quantity. The receiving tank and the bar screens are designed for the peak flow, but the units down stream of the equalization tank are designed for an average flow and an average quality. The energy consumption is approximately $0.9 \mathrm{kWh} / \mathrm{m} 3$ water treated and the cost is $12-20$ Rupees $/ \mathrm{m} 3(2-4 \mathrm{SEK} / \mathrm{m} 3)$ treated water.

\subsection{Flowchart for PCETP}

The flowchart for Wash water treatment plant in PCETP is shown in the Figure 1. A number is connected to every unit.

The bar screen (1) is where the wastewater first passes through and is situated in the influent of the Receiving sump (2). It is used to take care of rags and large objects in the wastewater, so that these objects do not destroy the forthcoming units, for example pumps. PCETP has two screens that are located inside the receiving sump. The shapes are rectangular, size $1.5 \times 2.5 \mathrm{~m}^{2}$. The clear openings (spaces between bars) of the first screen are 10-15 mm and clear openings of the second screen are $20 \mathrm{~mm}$. The screen is hand-cleaned once a day and this is sufficient because the character of the water is good.

The purpose of the receiving sump is to attain the same flow into the treatment plant. The diameter of the receiving sump is 8.0 meters and it has a depth of 2.3 meters. The flow into the treatment plant is about $132-150 \mathrm{~m}^{3} / \mathrm{h}$ and TDS is less then $2100 \mathrm{mg} / \mathrm{l}$. In general, TDS is around $1800 \mathrm{mg} / \mathrm{l}, \mathrm{pH}$ is about $8-9$ and the retention time in the tank is approximately 45 minutes. 
Afterwards the water is pumped to the equalization tank (3). The water is spread over three floating aerators, which distribute the water on to the surface of the equalization tank. The water is mixed with air so that an anaerobic process does not occur and settling of suspended solids is avoided. The equalization tank is there to equalize the temperature, quality and flow rate of the water. In other words, minimizing the fluctuation in those parameters for the downstream units. The equalization tank in PCETP has a diameter of 32 meters and a depth of 4 meters. The retention time in the tank is about 24 hours with a flow of $150 \mathrm{~m}^{3} / \mathrm{h}$.

The water is then again pumped to the flash mixing tank (4). The first goal for the mixing tank is to raise the wastewater $\mathrm{pH}$ to form metal hydroxide particles, by the addition of lime. The next step is to add iron sulphate and polyelectrolyte into the wastewater. Iron sulphate destabilizes the colloids so they are able to flocculate. The polyelectrolyte attaches to the metal solid particles and small metal hydroxide particles become entangled in the polyelectrolyte. This increases the particle size, which promotes settling. The mixing tank has a volume of $1.5 \times 1.5 \times 1.8 \mathrm{~m}^{3}$ and the mixer is mechanical. In PCETP they add lime to raise the $\mathrm{pH}$ to 11 . Water samples are collected about every two hours from the equalization tank so the dose of the chemicals can be regulated to the quality of the water. On average, the chemicals added in 1 liter wash water are $80-90 \mathrm{ml}$ Lime, $\mathrm{Ca}(\mathrm{OH}) 5 \%$ and $20 \mathrm{ml}$ iron sulphate, FeSO4 5\%. The water retention time in the flash mixing tank is about two minutes.

After that the water goes into the clariflocculator (5), where the particles coagulate and sink to the bottom as sludge. The deposited sludge is scratched off from the bottom of the tank and pumped into the sludge sump. The cleaner water reaches the top; it flows out through the outfall, which extends all around the settling tank.

The outlet water from the clariflocculator goes to the clarified effluent sump (6). The sump is used to provide a constant flow into the next unit, the AVG filter (7). The clarified effluent sump in PCETP has a retention time of 30 minutes. The dimension of the tank is $10.0 \times 6.0 \times 2.5 \mathrm{~m}^{3}$. The water is pumped by means of the automatic valves gravity filter feed pumps to the Automatic Valves Gravity Filter, AVGF. The purpose of the filtering is to remove suspended solids, which did not settle in the sedimentation basin. The reason the particles do not settle could be that they are too small and do not have sufficient time to settle. The particles instead follow the water out. The wastewater passes through the filter bed composed of granular material. The removed particles are accumulated in the voids in the sand therefore the head increases. When the pressure gets too high, automatic backwashing starts to remove the suspended solids. In PCETP, the sand filter is used because it is effective and made of cheap material. They have three different sand stones of a different density to increase the flow. The coarse material is on the bottom and the fine material on the top. The driving force in the sand filter is the capillary drainage system in the bottom. The flow in the filters is $7 \mathrm{~m}^{3} / \mathrm{h}$. This gives a retention time of approximately 10 minutes. The filter is backwashed for about 15 minutes with a flow of $50 \mathrm{~m}^{3} / \mathrm{h}$, in general twice a day. The backwash water from the sand filter goes back to the receiving sump.

After the AVGF, $\mathrm{HCl}$ is added and mixed into the water with a static mixer (8) to reduce the $\mathrm{pH}$ to 7.5-7.8. A static mixer is placed on the pipe to the stability tank and is designed with baffles. This mixes the water hydraulically with $\mathrm{HCl}$.

The water then goes to the stabilization sump (9), where the $\mathrm{pH}$ in the water stabilizes, resulting in fixed $\mathrm{pH}$ at 7.5-7.8 before the water goes to the carbon filter.

The water is pumped into an Automatic Carbon Filter, ACF (10). The most effective method to take away unwanted materials such as odour, heavy metals organic and inorganic pollutants is to use an ACF. Activated carbon can be prepared from anything consisting of carbon, for example hardwood or nut shell. The materials are heated to $200-1000^{\circ} \mathrm{C}$ without oxygen and are activated by reheating to a high temperature whilst providing steam. This will give a fine capillary structure with a surface area of $1000-2000 \mathrm{~m}^{2} / \mathrm{g}$. The carbon will adsorb the pollution and in that way remove the substance. PCETP has two granular carbon filters, one in each system. The volume of the tanks is $10 \mathrm{~m}^{3}$ and each tank is under a pressure of 2.5-3.5 $\mathrm{kPa}$. The retention time in ACF is eight minutes. The thickness of the carbon bed is 0.5-0.75 meter and it is made of coconut shells. The coconut shells are used for two years before they are replaced. The filter is backwashed every eight hours for 15 minutes. The back washing and the first filtrate go to the receiving sump.

After the ACF, the clean water goes through a magnetic flow meter (11), which registers TDS and pH. This unit forms the last control of the water before it goes to the field for irrigation. The effluent water has a flow of about $139 \mathrm{~m} / \mathrm{h}, \mathrm{pH}$ around 7.5 and a TDS of $1700 \mathrm{mg} / \mathrm{l}$. Finally the water is pumped with a booster pump out to the field for irrigation.

The sludge from the bottom of the clariflocculator goes to the sludge sump (12) and then further to the sludge thickener (13). The sludge sump is a tank where the sludge is collected before it goes to the sludge thickener. This tank is essential to achieve a constant flow into the next unit. The sludge sump in the treatment plant has a diameter of 1.5 meters and a depth of 3.0 meters.

The purpose of the thickener (15) is to increase the solids content of the sludge by removing a portion of the liquid fraction. The thickener has a slow speed mixer. The mixer has the function of making air channels in the sludge, which 
makes it easy for the water to escape. Another function of the mixer is to scratch the sludge into the middle of the tank where the sludge is taken out. In PCETP the sludge thickener has a diameter of 6.0 meters and a depth of 2.0 meters.

After the sludge thickener the sludge can go two different ways. The centrifugation(14) separates liquids from solids by considerably increasing the gravity power. Due to different density between the solids and the liquid the solids go immediately to the periphery and the water stays closer to the centre and can than be separated. PCETP has two centrifuges but only uses one at a time. The centrifuge extracts the water so the outlet DS is $25 \%$. Each day $10-15$ tons of sludge is produced.

The rest of the sludge goes to the drying beds (16). Sludge-drying beds are used to dewater digested sludge. The bed is similar to slow filtration through sand. The bed is filled up with one meter of sludge and it stays untouched for 20 days. Under the sand layer there are drainpipes to collect the separated water. After drying, the sludge is removed and packed into bags and stored under a roof. The sand has three different fractions to increase the flow speed through the bed. The five drying beds are a complement to the centrifuge. They are used instead of the centrifuge when capacity is not sufficient. The dimensions of each bed are $11 \times 5.0 \times 1.0 \mathrm{~m}^{3}$.

As a final point the sludge is packed in sacks and stored under a roof until further notice. PCETP has made an investigation regarding the use of sludge for brick production. The result was very positive (Charlotta Leissner, 2005).

\section{3. pH System Description in PCETP}

After the AVGF, $\mathrm{HCl}$ is added and mixed into the water with a static mixer to reduce the $\mathrm{pH}$ to $7.5-7.8$. The alkalinity of the solution leaving the $\mathrm{AVGF}$ is measured by a digital $\mathrm{pH}$ meter, whose output is used to regulate the $\mathrm{HCl}$ dosing pump to maintain the $\mathrm{pH}$ value ( 7.5 to 7.8$)$ in the static mixer, then goes to the stabilization sump as shown in the Figure.2.

\section{Results and Discussion}

The Figure. 3 shows the behavior of the output $\mathrm{pH}$ value with respect to $\mathrm{HCl}$ dosing. The $\mathrm{pH}$ value is maintained between $7.5-7.8$ by regulating the HCL dosing. Results are summarized in the Table.1, where the pH value observed before the dosage of $\mathrm{HCl}$ varies from 10.41 to 9.06 and after dosage of $\mathrm{HCl}, \mathrm{pH}$ value is controlled between 7.5 - 7.8.

\section{Conclusion}

Perundurai Common Effluent Treatment Plant, PCETP uses new technology and units to simplify operations. The plant is well operated and it has a constant effluent water quality. PCETP treats effluent water from 14 textile industries in the area. Tamil Nadu Pollution Control Board, TNPCB, regulates the limits for industries to dispose water. The 14 textile units in SIPCOT have started PCETP to achieve a good quality of the wastewater, so now it is the treatment plant's responsibility to follow the regulation. The limits TNCPB set up for disposal of wastewater on land is achieved with good margin at PCETP. $\mathrm{pH}$ is one of the important parameter because microbes used in biological treatment can only survive in a narrow $\mathrm{pH}$ range between roughly $\mathrm{pH}$ 6-8. The result shows that the $\mathrm{pH}$ value of the treated water is maintained between $7.5-7.8$ to save the microbes used in biological treatment as well as to reduce the wastage of chemicals.

\begin{tabular}{lll}
\multicolumn{2}{l}{ Nomenclature } \\
CETP & - & Common Effluent Treatment Plant \\
PCETP & - & Perundurai Common Effluent Treatment Plant \\
AVGF & - & Automatic Valves Gravity Filter \\
$\mathrm{ACF}$ & - & Automatic Carbon Filter \\
$\mathrm{TDS}$ & - & Total Dissolved Solids \\
$\mathrm{TSS}$ & - & Total Suspended Solids \\
$\mathrm{COD}$ & - & Chemical Oxygen Demand \\
$\mathrm{BOD}$ & - & Biological Oxygen Demand \\
$\mathrm{NaCl}$ & - & Sodium Chloride \\
$\mathrm{Ca}(\mathrm{OH})$ & - & Lime \\
$\mathrm{FeSO}_{4}$ & - & Iron Sulphate \\
$\mathrm{References}$ & &
\end{tabular}

Baskar, R., Meera Sheriffa Begum.K. M., \& Sundaram.S. (2006). Characterization and reuse of textile effluent treatment plant waste sludge in clay bricks. Journal of the university of chemical technology and metallurgy, 41, 473-478. 
Charlotta Leissner, Elisebeth Wegen (2005). Industrial waste water treatment at PCETP, INDIA-A primary investigation of heavy metal content. Master's Thesis 2005:28, Department of Civil and Environmental Engineering, Water Environment Technology, Chalmers University of Technology, 20-26.

Emerson Process Management, (2004). Basics of $\mathrm{pH}$ control, [Online] Available: http://www.emersonprocess.com/raihome/documents/Liq_AppData_43-001.pdf. (August, 2004).

OMEGA Engineering, (2006). Introduction to pH, [Online] Available: http://www.omega.com/techref/ph.html.

Shankar, U., (2003). Common effluent treatment plants: An institutional arrangement for pollution control for small scale tanneries in India. [Online] Available: http://www.elaw.org/assets/pdf/India2000.pdf.

Samiya Ahmed, Alexandra Clenett, Matthew Clark and Kelvin Tapley. (2006). Choosing an Effluent

Treatment Plant. [Online] Available: http://www.sei.se/water/beel/ETP.pdf. 
Table 1. Observation of $\mathrm{pH}$ system

\begin{tabular}{|c|c|c|}
\hline Before Dosage pH VALUE & HCI DOSING (ml) & After Dosage pH value \\
\hline 10.41 & 0.70 & 7.79 \\
\hline 10.26 & 0.60 & 7.56 \\
\hline 10.23 & 0.65 & 7.64 \\
\hline 10.16 & 0.60 & 7.51 \\
\hline 10.15 & 0.55 & 7.63 \\
\hline 10.03 & 0.50 & 7.66 \\
\hline 9.93 & 0.50 & 7.63 \\
\hline 9.89 & 0.50 & 7.62 \\
\hline 9.84 & 0.50 & 7.51 \\
\hline 9.84 & 0.40 & 7.78 \\
\hline 9.83 & 0.50 & 7.62 \\
\hline 9.83 & 0.50 & 7.54 \\
\hline 9.83 & 0.40 & 7.67 \\
\hline 9.82 & 0.40 & 7.75 \\
\hline 9.82 & 0.40 & 7.67 \\
\hline 9.81 & 0.40 & 7.77 \\
\hline 9.78 & 0.40 & 7.70 \\
\hline 9.75 & 0.50 & 7.59 \\
\hline 9.72 & 0.5 & 7.67 \\
\hline 9.67 & 0.4 & 7.58 \\
\hline 9.61 & 0.4 & 7.72 \\
\hline 9.55 & 0.3 & 7.62 \\
\hline 9.54 & 0.35 & 7.52 \\
\hline 9.48 & 0.35 & 7.62 \\
\hline 9.47 & 0.35 & 7.68 \\
\hline 9.43 & 0.35 & 7.79 \\
\hline 9.43 & 0.3 & 7.64 \\
\hline 9.42 & 0.28 & 7.74 \\
\hline 9.41 & 0.55 & 7.54 \\
\hline 9.40 & 0.28 & 7.68 \\
\hline 9.37 & 0.28 & 7.61 \\
\hline 9.35 & 0.27 & 7.73 \\
\hline 9.33 & 0.5 & 7.77 \\
\hline 9.33 & 0.35 & 7.59 \\
\hline 9.31 & 0.5 & 7.71 \\
\hline 9.21 & 0.27 & 7.69 \\
\hline 9.19 & 0.27 & 7.55 \\
\hline 9.16 & 0.4 & 7.64 \\
\hline 9.10 & 0.35 & 7.50 \\
\hline 9.06 & 0.30 & 7.53 \\
\hline
\end{tabular}




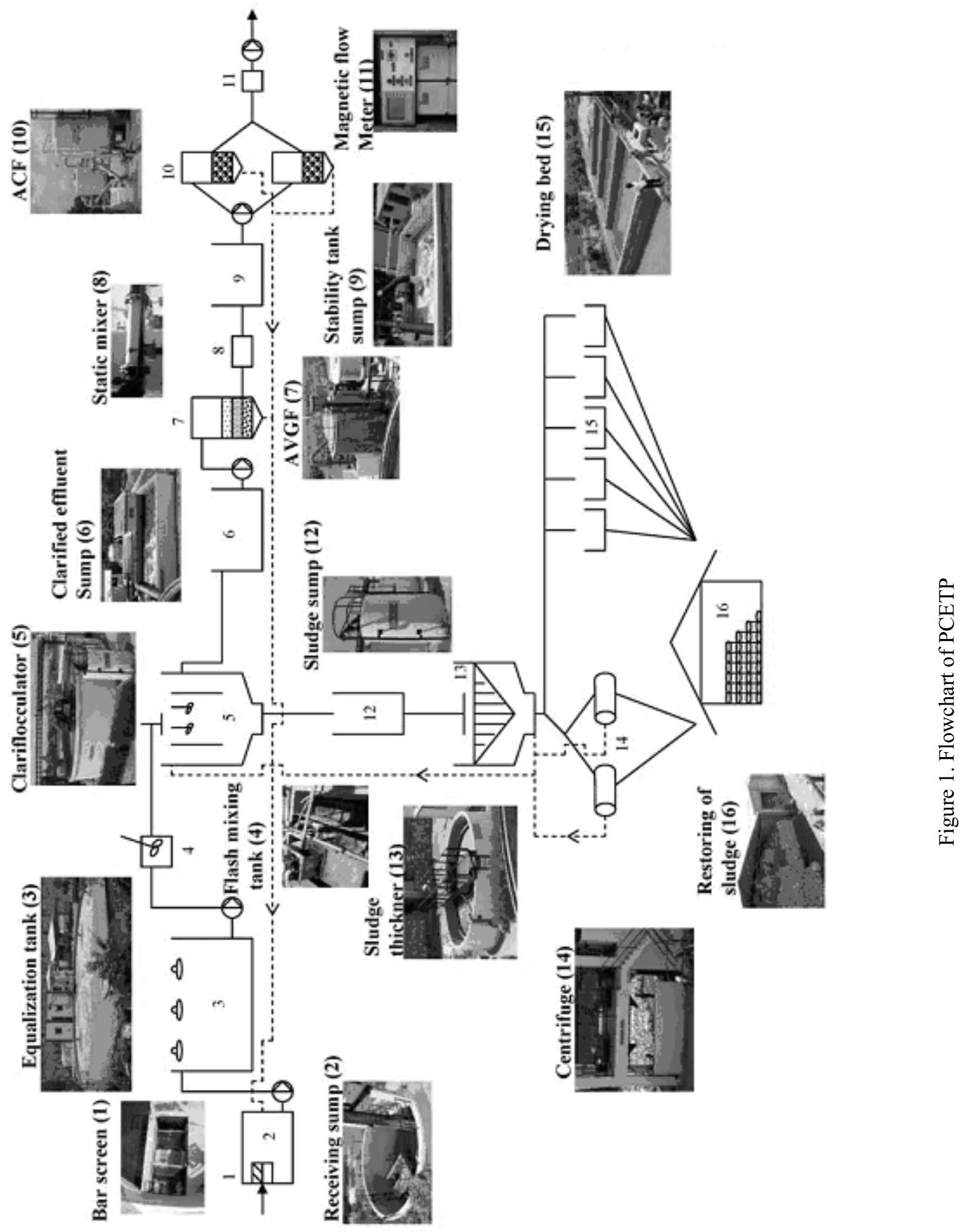




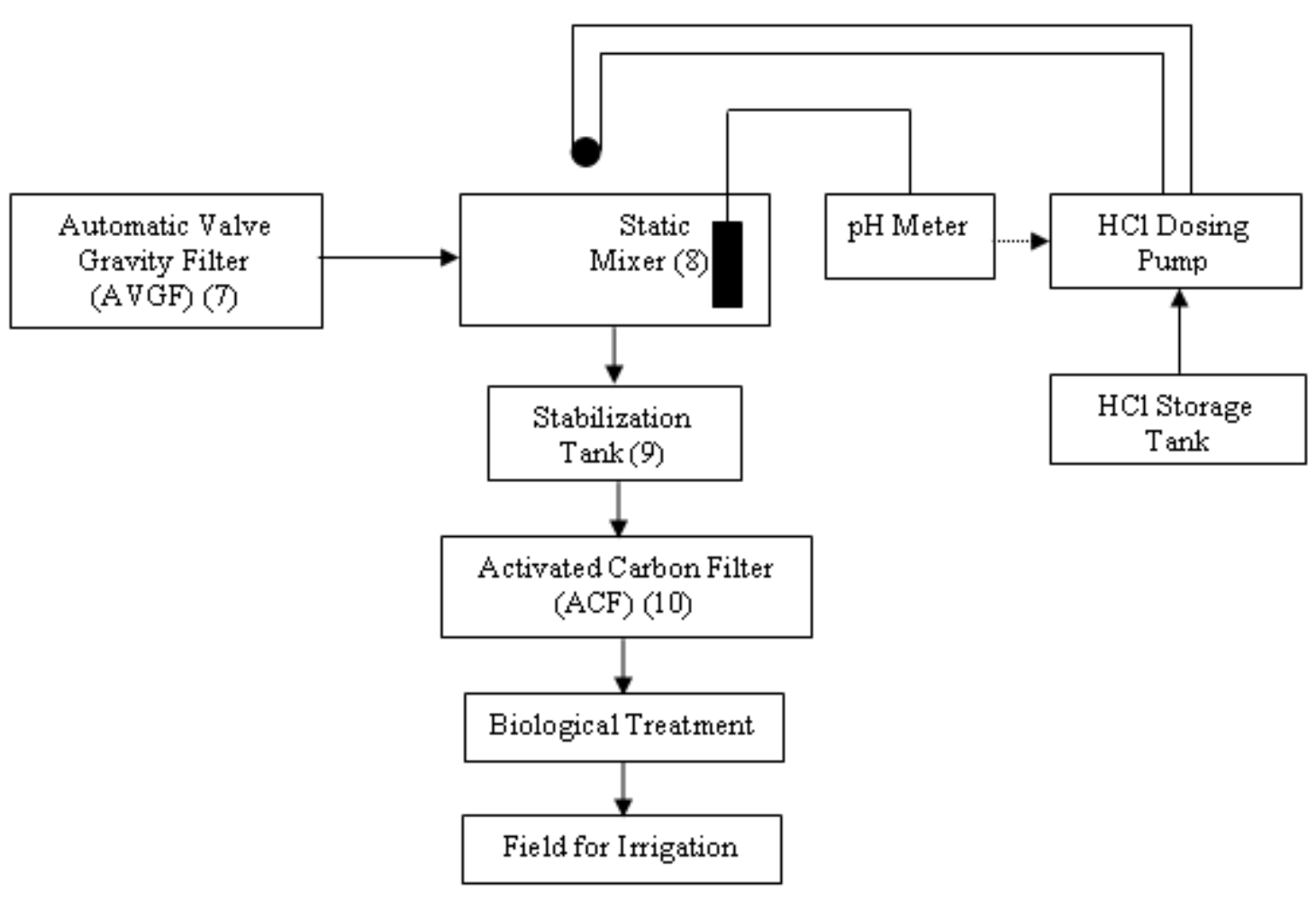

Figure 2. $\mathrm{pH}$ system description in CETP

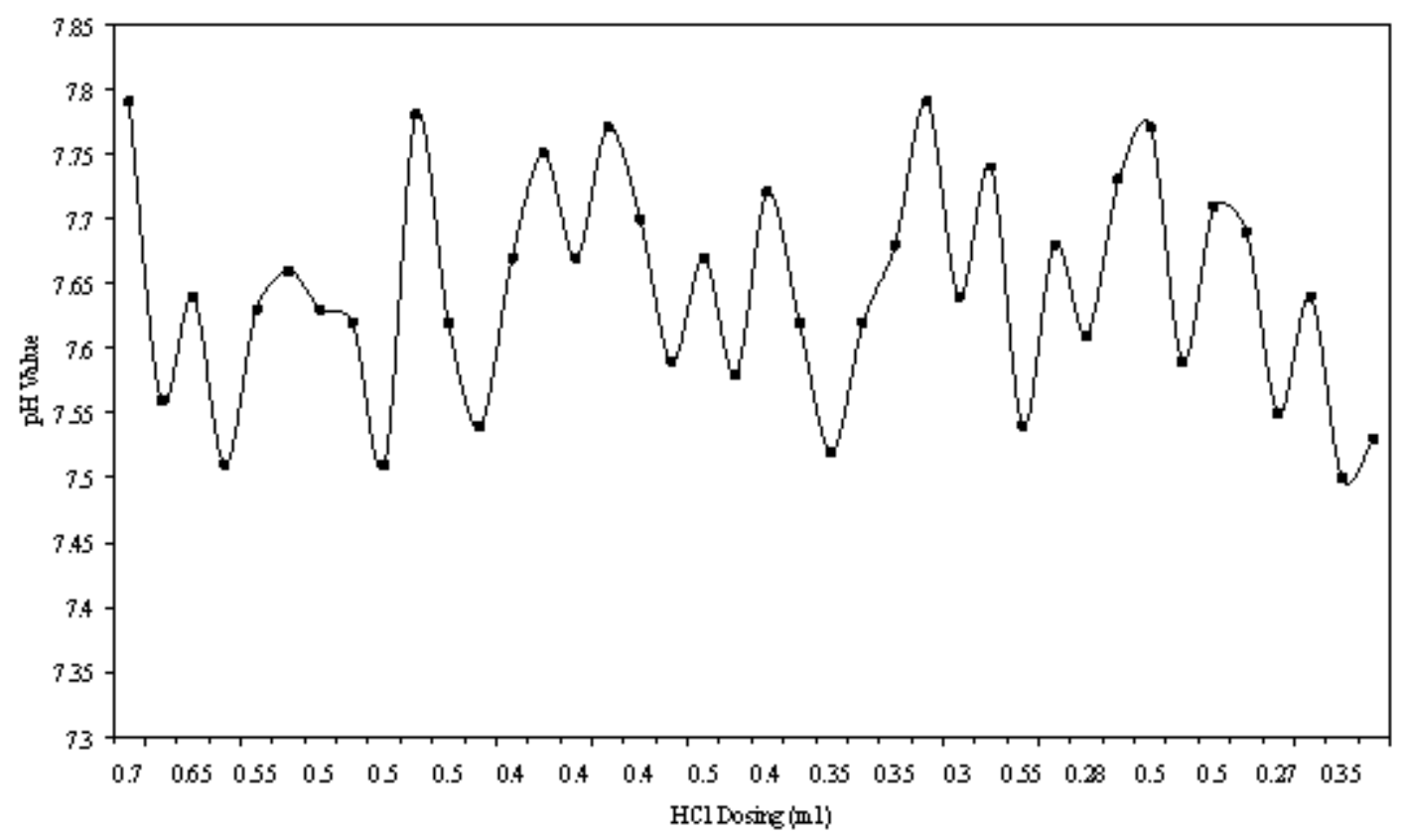

Figure 3. Response of $\mathrm{pH}$ System 